\title{
RELAXATION PROCESSES IN GLASSES AS SHOWN BY OPTICAL ATTENUATION EXPERIMENTS
}

\author{
F.F.Y. WANG ${ }^{*}$, J.P. ' 'AKIN, D.N. PAYNE and W.A. GAMBLING \\ Department of E! tronics, University of Southampton, Southampton $5095 \mathrm{NH}, \mathrm{UK}$
}

\begin{abstract}
Some optical attenuation experiments on both bulk glasses and cladded glass fibres (fibre optics) are described. They reveal the presence of relaxation processes in the glass in its transformation range.
\end{abstract}

The basic loss mechanisms giving rise to optical attenuation in glasses are not yet completely understood, but their basic features are well accounted for. In recent years, great strides have been made in the development of low-loss glasses. The result is the availability of glasses of exi ptional purity (less than $1 \mathrm{ppm}$ impurities). The resulting contribution to glass science can be very significant in the near future, quite apart from the immediate applications in optical communication systems.

Normal commercial glasses have at tenuation losses of greater than $10000 \mathrm{~dB} / \mathrm{km}$ within the visible spectrum [1]. As a point of reference, $200 \mathrm{~dB} / \mathrm{km}$ is approximately equivalent to a $1 \%$ transmission loss in a $25 \mathrm{~cm}$ length specimen. This type of highloss glass, when used as the cladding, contributes only a small amount to the total loss of multimode fibre optics. For example ME1 glass (Chance Pilkington) used as a cladding contributes $1-20 \mathrm{~dB} / \mathrm{km}$ to the fibre loss, in spite of having a bulk attenuation of $3000 \mathrm{~dB} / \mathrm{km}$. Imperfections such as bubbles and foreign particles, even in small amounts, produce very large losses. For instance $1 \mathrm{ppm}$ of platinum particles with $1 \mu \mathrm{m}$ size gives a loss of $900 \mathrm{~dB} / \mathrm{km}$. Consequently, such imperfections must be reduced to a very low level, in the cladding glass and particularly in the glass core. Inhomogeneity in the boundary between the cladding and the core, and bending of the fibre can contribute an attenuation of about $1-2 \mathrm{~dB} / \mathrm{km}$. The major limiting sources of attenuation loss are therefore scattering by the glass and absorption by impurities. Measurement of the angular distribution and the wavelength dependence shows that the scattering is close to Rayleigh in form. For example in both Schott F-7 bulk glass and fibres drawn with an F7 core and Chance-Pilkington cladding, the scattered light [2] has a $\lambda^{-n}$ dependence (where $n=4.1$ for fibre and 4.4 for the

\footnotetext{
* Permanent address: Department of Materials Science, State University of New York, Stony Brook, New York 11790, USA.
} 
bulk glass), with the bulk glass having the lower loss. Because of the strong wavelength dependence the scattering loss is high at the ultraviolet wavelengths but falls rapidly through the visible region to a level of only a few $\mathrm{dB} / \mathrm{km}$ in the near infra-red at $0.9 \mu \mathrm{m}$ which is the wavelength of interest for optical communications. The Rayleigh scattering loss is a function of the glass composition, but it is in the order of less than $40 \mathrm{~dB} / \mathrm{km}$ at wavelengths greater than $600 \mathrm{~nm}$. Lead glasses have a slightly higher Rayleigh scattering loss than soda-lime silicates, and fused silica has the lowest Rayleigh scattering loss. By and large, the absorption loss due to impurities assumes the predominant portion of the total optical attenuation loss except in the best available silica. As a rule of thumb, impurity contribution to the loss is very roughly $10 \mathrm{~dB} / \mathrm{km}$ per $1 \mathrm{ppm}$ but depends very much on the type and oxidation state of the impurity. Consequently, the elimination of impurities from the glass is a prerequisite for achieving low attenuation loss.

In the last two years, the lowest attenuation losses in glasses have been decreased from a level of $200 \mathrm{~dB} / \mathrm{km}$ to a level of $20 \mathrm{~dB} / \mathrm{km}$ [3]. In the particular case of doped silica fibres attenuations as low as $4 \mathrm{~dB} / \mathrm{km}$ have been achieved [4]. Thus new standards of purity of glass and silica are attainable and thus the new data on optical attenuation in glasses are relevant to all glass scientists.

At the University of Southampton, techniques and equipment have been developed for investigations of optical scattering [2,5] and optical absorption loss [6, 7]. Extensive measurements have been made on bulk glass specimens [8] (up to $30 \mathrm{~cm}$ length) and on cladded glass fibres [9] (up to $1 \mathrm{~km}$ length). In the following, several sets of experimental data, pertaining to the effect of heat treatment, are described which allow comparisons between bulk glass specimens and cladded glass fibres and which are very illuminating. The fibres were drawn using the rod-and-tube technique in an equipment [9] having a high degree of control over the furnace temperature and the pulling speed. The resulting dimensional accuracy is such that the overall diameter [10] varies by less than $1 \mu \mathrm{m}$ in several hundred metres.

In fig. 1, optical attenuation loss curves, for the wavelength range 0.5 to $1.0 \mu \mathrm{m}$, of Schott F-7 bulk glass first in the form of a redrawn sample as supplied, and then after heat treatment, are presented. The heat treatment consisted of holding the glass specimen for $4 \mathrm{~h}$ at $450^{\circ} \mathrm{C}$ and cooling it to room temperature over a period of $12 \mathrm{~h}$. This heat treatment produced an overall lowering of the attenuation loss by the amount of $60 \mathrm{~dB} / \mathrm{km}$. In fig. 2 [9], optical attenuation loss curves of cladded glass fibre (Schott F-7 glass core with ME-1 cladding) are presented. In this case the heat treatment consisted of a constant temperature soak at $460^{\circ} \mathrm{C}$ for $2 \frac{1}{2} \mathrm{~h}$ followed by a natural furnace cool at the rate of $60^{\circ} \mathrm{C} / \mathrm{h}$. Again, the heat treatment reduced the attenuation loss over the whole wavelength range by a uniform amount of 150 $\mathrm{dB} / \mathrm{km}$. Moreover, in fig. 2, the attenuation loss curve of an annealed bulk F-7 glass rod is also shown and is in close agreement with that of the heat-treated fibre. This seems to indicate that it is possible to make fibres with the same loss as that of the starting glass, using the rod-and-tube technique. These data show that relaxation processes occur in the glass during the heat treatment process. 


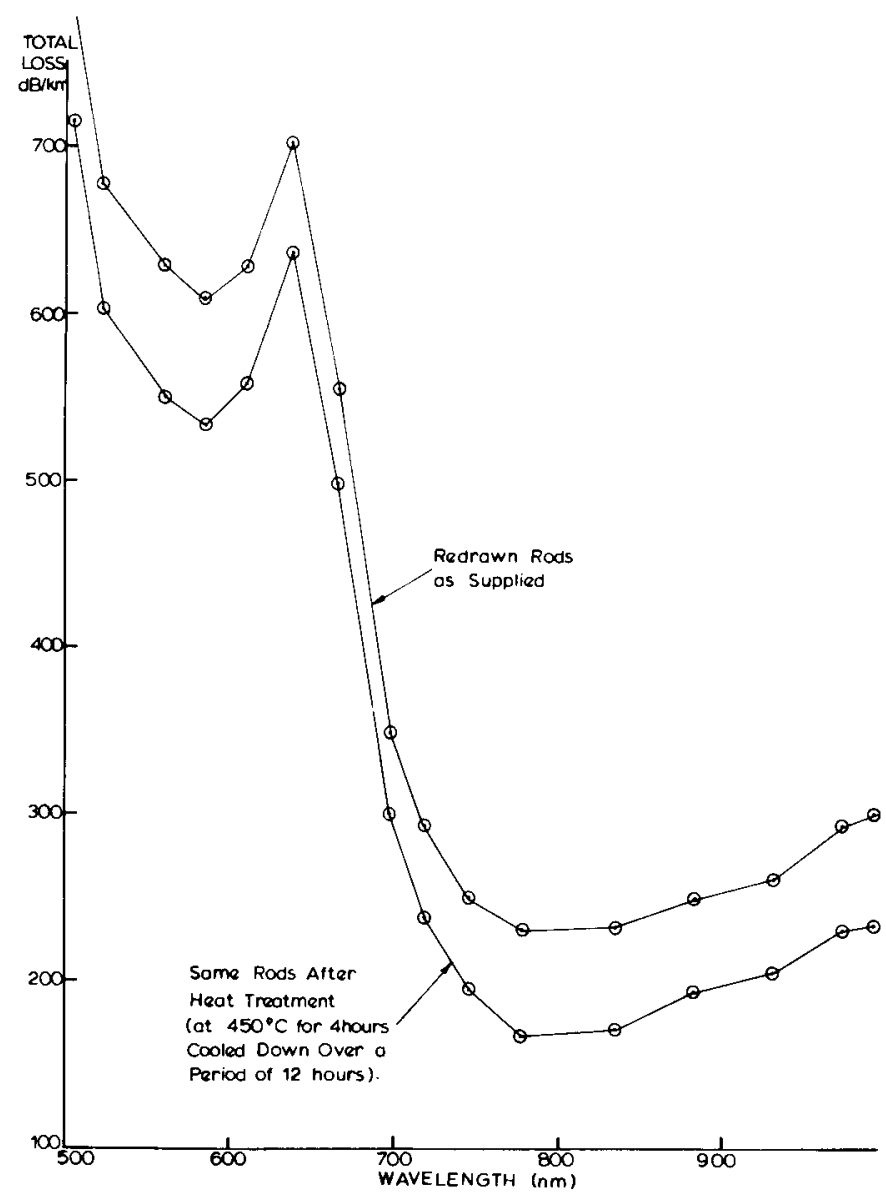

Fig. 1. Total optical attenuation loss as a function of wavelength for Schott F-7 glass rods before and after heat treatment. Each curve is the average of three separate measurements on a doublebeam spectrophotometer with repolishing of end surfaces to avoid errors due to differing end losses (after Dakin and Gambling [10]).

Experiments have also been conducted on cladded glass fibres and the at tenuation loss was measured during the heat treatment. Detailed discussion of these experiments will be reported in a future publication [11]. A representative curve is presented here in fig. 3. The cladded glass fibre used consisted of an $80 \mu \mathrm{m}$ diameter special lead glass core with a borosilicate glass cladding, supplied by the University of Sheffield. The data were taken at a wavelength of $600 \mathrm{~nm}$ where the attenuation loss of the cladded fibre prior to heat treatment was $220 \mathrm{~dB} / \mathrm{km}$. The furnace temperature was maintained at $340^{\circ} \mathrm{C}$. The cladded fibre, having a total length of $20.7 \mathrm{~m}$ 


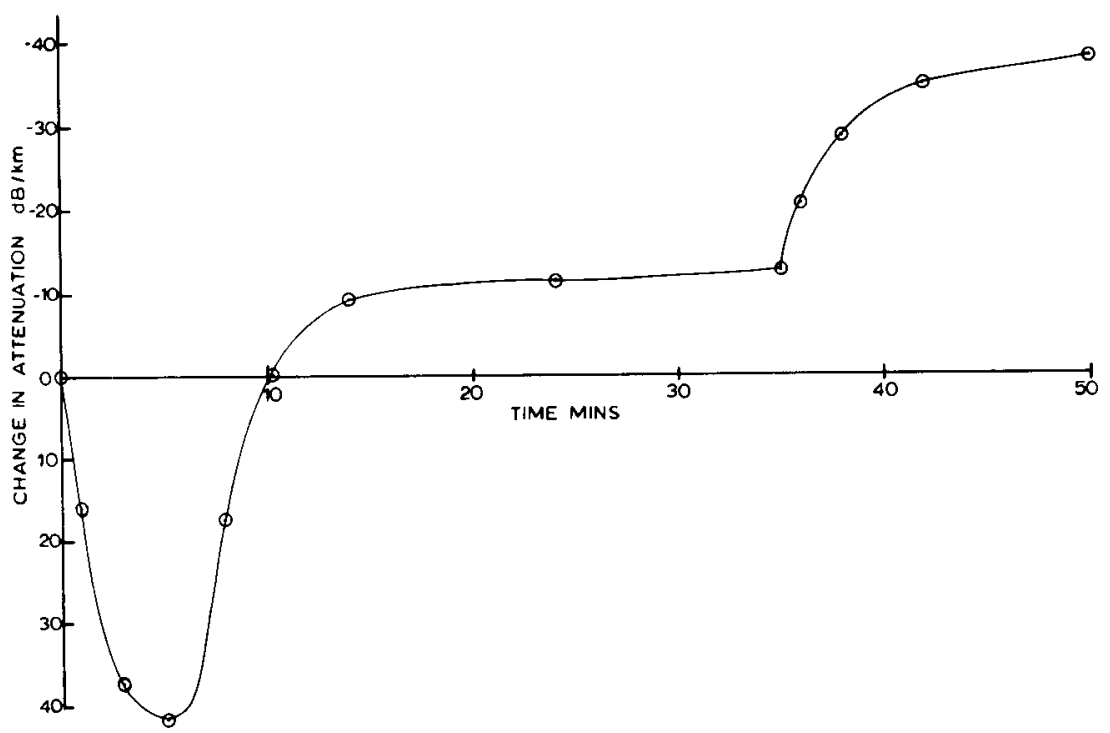

Fig. 2. Optical attenuation losses as a function of wavelength for a cladded glass fibre before and after heat treatment. The core was Schott F-7 glass and the cladding was Chance-Pilkington ME-1 glass (after Payne and Gambling [11]). A curve for bulk F-7 glass is also included.

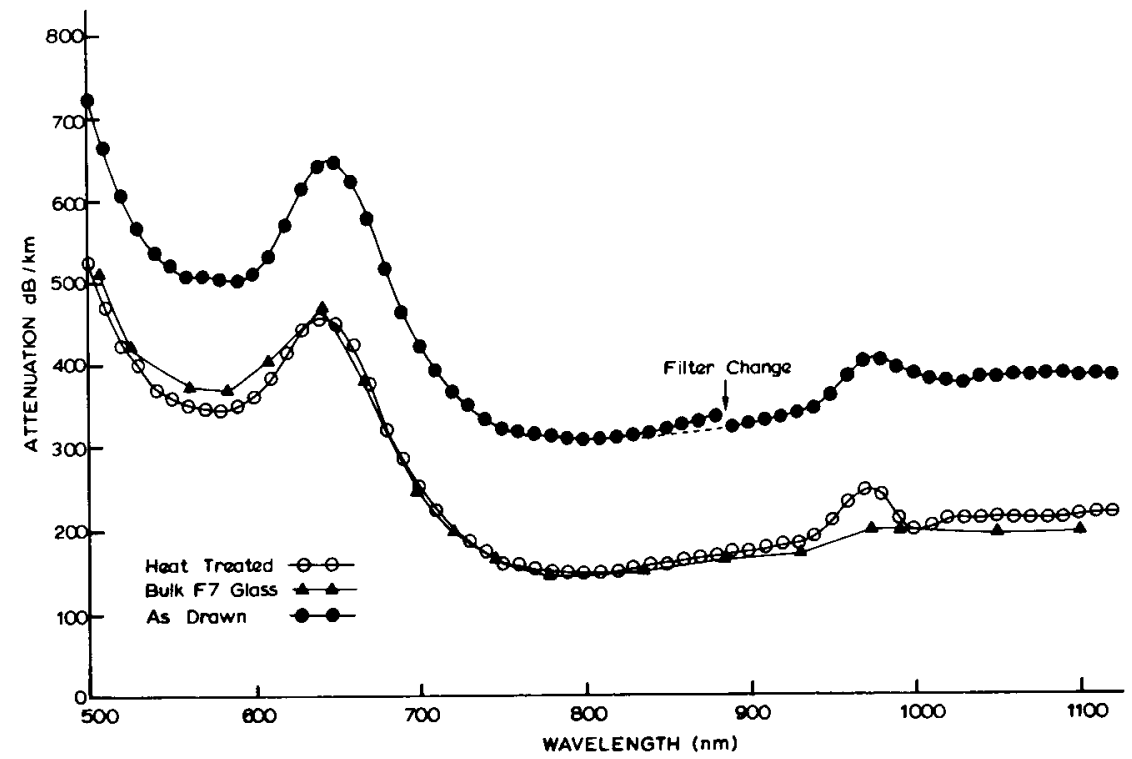

Fig. 3. The change in optical attenuation loss at $600 \mathrm{~nm}$ as a function of soaking time at $340^{\circ} \mathrm{C}$ for a $20.7 \mathrm{~m}$ length, cladded glass fibre. Core and cladding glasses are from special melts supplied by the University of Sheffield (after Payne and Gambling [11]). 
was wound on a $11 \mathrm{~cm}$ diameter pyrex pipe, and $90 \%$ of the fibre length was placed inside the furnace. The time duration of the heat treatment was counted from the time of its insertion into the furnace. The curve in fig. 3 can be divided into three segments. The first segment is the result of the rise in temperature which always increased the attenuation loss. The second segment is the result of heat treatment which decreased the loss. The combination of these two effects produces the first maximum in the attenuation loss. Because such combinations are complex in nature, the increase in attenuation loss at the maximum does not have a simple functional temperature dependence. However, higher heat-treating temperatures produce greater increases in attenuation loss. An independent experiment with the same cladded glass fibre produced a decrease of $16 \mathrm{~dB} / \mathrm{km}$ when it was placed in liquid $\mathrm{N}_{2}$ bath, while heating to $340^{\circ} \mathrm{C}$ produced an increase of $40 \mathrm{~dB} / \mathrm{km}$ [11]. Referring again to the experiment described by fig. 3 , when the attenuation loss value appeared to reach a plateau in the second segment, the fibre was taken out of the furnace. Its attenuation loss in this third segment is the result of cooling, which always decreased the attenuation loss.

The amount of decrease in attenuation loss through cooling was of the same order of magnitude as the amount of increase through heating, but they have no direct correlation. All the heat treatment experiments were conducted thus far only on cladded glass fibres after their being formed in the fibre-pulling apparatus. Experiments have been done to establish whether or not these heat treatment effects are repeatable, and these show that the second section of the curve is not reversible.

Analysis of a number of heat-treatment curves such as that shown in fig. 3 reveals that none of the time segments can be fitted to any simple exponential function or diffusional type of $t^{1 / 2}$ functional dependence. Each segment appears to be complex in nature, and can only be fitted by superposition of functions. With cognisance of the lack of physical reality for the 'relaxation time' $\tau$ given in the fitted exponential functions, as indicated in the preceding paper by Douglas [12], it is nevertheless interesting to mention that the 'relaxation time' $\tau$ values, obtained form curves such as fig. 3, were of the order of the order of $100 \mathrm{sec}$. Such values are considerably shorter than the usual relaxation times for this temperature range.

In summary, this paper shows how optical attenuation loss data can give an interesting insight into the fundamental properties of glass and the use of fibres enables extinction coefficients to be measured which are too small to be measured in bulk glass. In particular, heat treatment data of the type shown here provide an interesting method of studying relaxation processes in glass.

\section{Acknowledgement}

One of the authors (F.F.Y.W.) expresses his gratitude to Professor W.A. Gambling and staff at the Department of Electronics for their encouragement and hospitality. $\mathrm{He}$ is also greatly indebted to the Science Research Council for the award of a Visiting 
Senior Fellowship which aided his sabbatical leave at the University of Southampton considerably.

\section{References}

[1] D.N. Payne and W.A. Gambling, Elec. Letts. 8 (1972) 374.

[2] J.P. Dakin and W.A. Gambling, Optics Commun. 6 (1972) 235.

[3] T. Uchida, M. Furukawa, I. Kitano, K. Koizumi and H. Matsumura, IEEE J. Quantum Electronics QE-6 (1970) 606.

[4] D.B. Keck, R.D. Maurer and P.C. Schultz, Appl. Phys. Lett. 22 (1973) 307.

[5] P.J.R. Laybourn, J.P. Dakin and W.A. Gambling, Opto-Elect. 2 (1970) 36.

[6] P.J.R. Laybourn, W.A. Gambling and D.T. Jones, Opto-Elect. 3 (1971) 137.

[7] J.P. Dakin, W.A. Gambling, D.N. Payne and H.R.D. Sunak, Optics Commun. 4 (1972) 354.

[8] J.P. Dakin and W.A. Gambling, Opto-Elect. 5 (July 1973) to be published.

[9] D.N. Payne and W.A. Gambling, Opto-Elect. 5 (July 1973) to be published.

[10] J.P. Dakin and W.A. Gambling, to be published.

[11] D.N. Payne and W.A. Gambling, to be published.

[12] R.W. Douglas, Proc. Third Rolla Ceramic Materials Conference, Baden-Baden, June 1973, J. Non-Crystalline Solids 14 (1974) 1. 